\title{
Epidemiology, risk factors, symptomatology, TNM classification of Non Small Cell Lung Cancer. An overview while waiting the $8^{\text {th }}$ TNM classification
}

\author{
Konstantinos Grapatsas ${ }^{1}$, Vasilis Leivaditis ${ }^{1}$, Zoi Tsilogianni ${ }^{2}$, Eugene Haussmannn ${ }^{1}$, Vasili Kaplunov ${ }^{1}$, \\ Michael Dahm ${ }^{1}$, Paul Zarogoulidis ${ }^{3 凶}$, Wolfgang Hohenforst-Schmidt ${ }^{4}$, Kosmas Tsakiridis ${ }^{5}$, Cristoforos \\ Foroulis $^{6}$, Dimitrios Paliouras ${ }^{7}$, Nikolaos Barbetakis ${ }^{7}$, Basili Kosan ${ }^{1}$ \\ 1. Department of Cardiothoracic and Vascular Surgery, Westpfalz Klinikum, Kaiserslautern, Germany. \\ 2. 1st Department of Internal Medicine, 401 General Military Hospital, Athens, Greece. \\ 3. Pulmonary Department-Oncology Unit, “G. Papanikolaou” General Hospital, Aristotle University of Thessaloniki, Thessaloniki, Greece. \\ 4. Medical Clinic I,'Fuerth" Hospital, University of Erlangen, Fuerth, Germany. \\ 5. Cardio-Thoracic Surgery Department, "Saint" Luke, Private Hospital, Panorama, Thessaloniki, Greece. \\ 6. Cardio-Thoracic Surgery Department, "AHEPA" University General Hospital, Aristotle University of Thessaloniki, Thessaloniki, \\ Greece. \\ 7. Thoracic Surgery Department, Theagenio Cancer Hospital, Thessaloniki, Greece.
}

$\square$ Corresponding author: Paul Zarogoulidis, M.D, Ph. D. Pulmonary Department-Oncology Unit, “G. Papanikolaou” General Hospital, Aristotle University of Thessaloniki, Thessaloniki, Greece. Fax: 00302310992424 Mobile: 00306977271974 E-mail: pzarog@hotmail.com.

(c) Ivyspring International Publisher. This is an open access article distributed under the terms of the Creative Commons Attribution (CC BY-NC) license (https:// creativecommons.org/licenses/by-nc/4.0/). See http://ivyspring.com/terms for full terms and conditions.

Received: 2016.08.03; Accepted: 2016.09.05; Published: 2017.01.01

\begin{abstract}
Lung cancer is a primary health issue which preoccupies the health professional community worldwide. Lung cancer is one of the leading causes of death in both men and women in the developed countries. It is mainly divided into two types. The non small cell lung cancer (NSCLC) and the small cell lung cancer (SCLC). The NSCLC is the most common type and consists the $87 \%$ of lung cancer overall. The staging and the therapeutic approach of NSCLC is based on TNM classification system. Currently the $7^{\text {th }}$ revision is being used for the appropriate classification of the cancer stadium. By the end of 2016 a new $8^{\text {th }}$ TNM classification is awaited.
\end{abstract}

Key words: Lung cancer, Smoking, Asbestos, Radon, lung cancer symptomatology, TNM.

\section{Introduction}

The lung cancer is one of the leading mortality etiologies in the USA (1). Lung cancer (LC) is mainly divided into two types: Non small cell lung cancer (NSCLC) and small cell lung cancer (SCLC). The NSCLC includes $87 \%$ of lung cancer cases with its most common types to be squamous cell carcinoma, large cell carcinoma, and adenocarcinoma. Adenocarcinomas account for approximately $40 \%$ of lung cancers. Squamous cell carcinomas are about $25 \%$ to $30 \%$ and large cell (undifferentiated) carcinomas about $10 \%$ to $15 \%$ of all lung cancers.
There are also some other rare types of non-small cell lung cancer, such as pleomorphic, carcinoid tumor, salivary gland carcinoma, and unclassified carcinoma. All subtypes of lung cancer may occur in atypical histologic variants as well as in mixed cell-type combinations.

The most clearly related cause of LC is the consumption of tobacco products (1-3). As by the end of 2016 a new $8^{\text {th }}$ TNM classification is awaited, the aim of this overview is to investigate the primary approach of LC and especially of the NSCLC. For this 
reason, the basic aspects of NSCLC are reviewed. An overview of epidemiology, clinical manifestations, risk factors, description of 7 th revision of the TNM classification of the stadiums of NSCLS and possible changes in the forthcoming TNM classification has been carried out in this review study.

\section{Epidemiology}

Only in the year 2008 six million new patients were diagnosed with LC worldwide. LC is the most common cancer type worldwide among men and the fourth most frequent among women. In the US, LC was the cause of $28 \%$ of all deaths due to cancer for the year $2012(4,5)$. In 2016 in the same country 224,390 new cases of lung cancer were registered. 117,920 of those cases concerned male and 106,470 female patients. During the same year 150,080 deaths involving LC occurred, 85,920 of which were male and 72,160 were female patients. Among the male population it was the second most frequently diagnosed cancer in the US (14\%) following prostate cancer. As long as the female population is concerned, LC was the second most diagnosed type of cancer after breast cancer in the US, occurring by $13 \%$. Regarding the calculated deaths among men and women it was the leading cause of death in the US with $27 \%$ and $26 \%$ respectively (1). However, the prevalence of LC statistically appears to be declining in America since the 1980s (2).

Epidemiologically the prevalence rates of LC seem to be higher in the developed and industrialized countries in America and Northern Europe than in the developing countries of the world $(2,6)$. The highest mortality rates in Europe are observed in Hungary and Serbia (2). The Southern European countries also present high rates of LC $(4,5)$. Generally, in 2012 the incidence of LC was $27,4 \%$ in both sexes in the western world (5) . High diagnostic rates and high mortality are encountered in men in Southern Europe, East Asia, South Africa and the Far East. The percentages of LC in women in these areas is significantly lower $(4,5)$. In western culture, where the smoking habit has become more mature, more women smoke than before. For example, young girls between 13-15 years old smoke at the same rate as the boys of the same age. The incidence rates of LC are therefore expected to increase in the female population in the years to come (3). The lowest rates of LC diagnosis are encountered in central Africa whereas the documented data in these countries are rather poor (2).

Historically, about one century ago, LC was considered to be a rare clinical entity $(4,7)$. It was for the first time observed in workers in 1400 (4).
However, with the high increase of tobacco consume during the 20th century also increased and the prevalence of this form of cancer $(4,7)$. In particular, it is believed that the current LC epidemiological occurrence is due to the increased smoking rates in the decades of 1940 and 1950 (7).

\section{Risk factors}

Smoking remains the leading cause and risk factor of LC (1-8). This form of cancer is related to the number of cigarettes smoked as well as the total duration of tobacco smoking during a person's life. Smokers are consequently in a significantly higher risk to develop LC than the non-smokers $(2,9,10)$. $90 \%$ of deaths caused by LC in men are considered to be mainly because of smoking (1). This relationship has been demonstrated by epidemiological studies and pathological changes in animal samples of lung tissue following exposure to cigarette smoke $(7,8,10$, 11). Since 19005.5 trillion cigarettes are estimated to have been consumed worldwide $(3,8)$. This may be due to the two great world wars that mankind experienced in the 20th century during which a mass distribution of cigarettes to fighting sholdiers took place (8). In the male population of developed countries a gradual stabilization of the incidence of LC has been observed (3). In the US, for example, there is a gradual decrease in the number of smokers. The total number is however still large. Smokers in this country are estimated at 42 million (2). However, in women an increased incidence of LC has been observed and this is because of the significant increase of the smoking habit among the female population. In countries in which the smoking habit has been reduced, the incidence of $\mathrm{LC}$ also tends to be reduced. On the other hand, due to increased smoking in developing countries it is expected that in these countries the incidence of LC among smokers will eventually be increased. In China, for example, where smoking rates are rapidly increasing, only in 2009 2,500 cigarettes were consumed pro capita (3). For this reason, in this country a rapid increase of LC is expected to occur $(1,3)$. In the European Union, Greece has one of the highest rates of lung cancer under the age of 45 years. This is because of the early onset of smoking from a large portion of the population $(3,12)$.

There are also indications that second-hand smoking (passive smoking) also contributes to the development of the disease $(13,14)$. Passive smoking has been blamed for the $1.6 \%$ of total cases of LC (1). This hypothesis was firstly made in the 1980s and it was associated with LC in women and children of smokers $(13,14)$. The relationship appears to be dose-dependent. It is interesting that in this patient 
group SCLC seems to be the most common type. The second hand smoking at home is also believed to have a greater impact on the appearance of LC than the second hand smoking exposition in the office (14). The exposure during childhood increases the risk of developing LC in adulthood to 3.6 times (1). This must be due to the fact that the home exposure is greater in duration and intensity than in other areas. As a result, wives and children of smokers are more likely to develop LC than other people around them (14). The probability of a non-smoker to develop LC due to passive smoking is estimated up to $25 \%(2,4$, 15). Based on this fact and on the high percentage of second hand smoking in certain countries LC is expected to dramatically increase (3). For example, in 2010 in some countries such as Greece, Turkey, Romania and Poland the exposure to second hand smoke reached up to more than $80 \%$ (3). In the other European Union countries second hand smoke exposure reaches up to $40 \%$ (3).

Radon exposure is the second most important cause of lung cancer, following tobacco smoke (16, 17). Radon gas is formed during the radioactive decay of uranium-238 $(2,18,19)$. Radon is regarded as an independent risk factor for LC (16). It has a well established relation with lung cancer in miners working in uranium mines (2). The residential exposure to radon has also been considered to have a connection with LC in non-smokers, without this relation to be clear according to the existing literature $(2,18)$. The risk of LC is higher in persons who are both exposed to radon und are also smokers (16). To sum up it is believed that radon is responsible for $2-3 \%$ of lung cancer cases annually (2). Asbestos is also an important environmental risk factor which is directly involved in the development of $\operatorname{LC}(1,4,20$, $21)$. The silicate type of asbestos fibers is considered to be a dangerous carcinogen agent (2). These asbestos fibers are naturally occurring in rocks and soils (20). Historically, asbestos exposure has been strongly associated with mesothelioma and lung cancer $(2,20$, 21). The risk of developing lung cancer increases by 5 times by direct expose to asbestos (2). This risk is higher in cases where asbestos exposure and smoking coexist $(2,20,21)$.

Patients with HIV infection are also thought to be a high risk group concerning the developing lung cancer $(2,22,23)$. The most common subtype of NSCLC in this patient group is adenocarcinoma. It seems that the risk is higher in patients who are or used to be smokers (23). However this statement is under debate (22).

Air pollution environmental factors seem to play a significant role in developing lung cancer as well (1,
2). Beryllium, nickel, copper, chromium, and cadmium are for instance some of the agents which have been connected with high risk of developing lung cancer (2). In Europe air pollution is accused to having played a role in the development of $11 \%$ of LC (1). In addition, several other aspects of the everyday life have been investigated. Dietary fiber and vegetables seem to protect humans from cancer $(1,2)$. Exercise also seems to have a protective effect against cancer (1). Underlying lung diseases may also play a role in developing lung cancer. Tuberculosis, emphysema and COPD have been accused for facilitating the progress of lung cancer (24-26).

Genetic predisposition is a current and widely investigated matter of study. The history of LC in the family rises the risk of the disease. The severity of the genetic predisposition can be demonstrated in cases of young patients. Epidemiologic and survival differences can be seen between patients with positive and those with negative family history of cancer. Family history is therefore considered to be an important factor of clinical features and serves as a prognostic indicator for $\operatorname{NSCLC}(27,28)$. In addition, current research is focused on the molecular etiology of NSCLC. The Epidermal growth factor receptor (EGFR), Kirsten rat sarcoma viral oncogene homolog (KRAS), and anaplastic lymphoma kinase (ALK) mutations have been particularly studied as possible causes of NSCLC (4).

Table 1. Risk factors of NSCLC.

Risk factors in Non-Small cell lung cancer

Smoking

Second hand/ passive smoking

Radon

Asbestos

HIV infection

Beryllium

Nickel

Copper

Cadmium

Tuberculosis

Emphysema

COPD

\section{Symptomatology}

The diagnosis of the NSCLC can be difficult, because most patients are asymptomatic $(2,29)$. Symptoms can, however, exist. In most cases when typical symptomatology occurs, the progress of the disease is already advanced (2). In addition, the 
patient may have symptoms as, for example cough, hoarseness or increased sputum because of smoking. The change or the deterioration of these sign and symptoms can lead the patient to visit his doctor and undergo further diagnostic control. These symptomatology can be due to the local spread of the disease, a metastatic disease or due to the presence of paraneoplasmatic syndroms $(2,29)$. At the point of the initial diagnosis of the NSCLC $20 \%$ of the patients have a localized disease, $25 \%$ a regional metastasis and $55 \%$ have a distant spread of the cancer disease (2).

The main symptoms of NSCLC are cough, chest pain, shortness of breath, coughing up blood, wheezing, hoarseness, recurring infections such as bronchitis and pneumonia, weight loss, loss of appetite and unusual fatigue $(2,29,30)$. Other symptoms that may appeare in patients with NSCLC and are due to local advance of the cancer disease may be some of the following: phrenic nerve paralysis, dysphagia, stridor, superior vena cava syndrome, pleural effusion, pericardial effusion, Pancoast syndrome, evidence of lymphangitic spread and cancer cachexia. Symptoms from extrathoracic organs may present due to the metastatic spread of the disease. For example, brain or bone metastases or spread to liver or to the adrenal glands or spread to the intraabdominal lymph nodes are just some of the remoted manifestations of the disease that may coexist. Coughing can be a very distressing symptom (31). It can be present in more than $65 \%$ of patients with lung cancer. Productive cough can be a primary symptom in $25 \%$ of lung tumors. However, chronic cough appears in less than $2 \%$ of lung cancer cases (32). It can coexist with sputum by smokers. It can be caused in NSCLC from postoperative pneumonia or lymph node enlargement that obstruct the lung bronchus (33). For this reason, if the involvement of a malignancy by persistent cough is suspected a bronchoscopy is indicated (32). Hemoptysis can also occur in any form and grade, from massive blood loss to bloody stigmata in sputum. However, this condition is rarely severe (33). Dyspnea may also appear in many cases. This can be due to atelectasis of the lung or a lobe or even due to pleural effusion, hemidiaphragm paralysis, pneumothorax or cardiac tamponade as a consequence of pericardial effusion $(2,29,30,33-35)$. Chest pain can also be present in patients with NSCLC. In cases of infiltration of the chest wall, patients may complain of dull persistent pain. This pain is connected neither with breathing nor with coughing. Retrosternal pain can indicate massive hilar or mediastinal nodal involvement. Localized pain can be caused from direct invasion of the tumor in the chest wall or rib metastases $(33,36)$. Dysphagia can be due to direct infiltration of the esophagus (37), mediastinal disease $(33,38)$, cervical lymphadenopathy, brainstem lesions $(38,39)$ gastrointestinal tract metastases (33, 38), oropharyngeal and esophageal infections and radiation-induced oesophageal toxicity (38). The heart or the pericardium may be affected in $20 \%$ of the cases either directly from tumor infiltration or indirectly because of lymphocytic or hematogenous metastases. Malignant pericardial effusion can be often in lymphatic spread of the tumor $(33,40)$. Arrhythmias can also been present $(40,41)$, while myocardial infarction has also been diagnosed as a result of the compression of the coronary arteries (40).

Some lung cancer cases involve syndromes that separately cause specific symptoms. Horner syndrome can appear due to an infiltration of the sympathetic nerve supply. Clinically it is characterized by miosis, partial ptosis and hemifacial anhidrosis or anhidrosis of the upper limb. It is typically observed in cases of Pancoast tumors (29, 42). These malignant tumors are characterized by a malignant neoplasm of the superior sulcus of the lung with destructive invasion of the thoracic structures, the brachial plexus and cervical sympathetic nerves. These tumors are usually NSCLC tumors, mainly of squamous cell origin. They are followed by adenocarcinomas and the large cell carcinoma subtype $(33,42)$. Patients with pancoast tumors can complain of shoulder or arm pain. This symptomatology can lead them to an orthopedic specialist and this might cost a lot of time concerning the final diagnosis of the Pancoast tumor. For this reason, in cases of shoulder or arm pain that persists for more than 15 or 20 days an investigation of thorax with a chest X-Ray should always be considered (29, $42,43)$. Superior vena cava syndrome is caused from the obstruction of the blood flow due to the compression of the superior caval vein by the lung tumor. It can be commonly manifested as headache, shortness of breath and rarely as cough, pain and dysphagia. Clinically swelling in the face, neck, arms, and upper chest may also be appear. This syndrome is an oncological emergency. The main histological types that cause it are the SCLC and squamous cell carcinoma $(29,44,45)$. The tumor infiltration of specific nerves can also to a relevant symptomatology. For instance, infiltration of the phrenic nerve can lead to elevation of the hemidiaphagm. In addition, infiltration of the left recurrent laryngeal nerve can cause hoarness (29).

Symptoms can also exist because of the presence of distant metastases. The most common metastatic 
site are the bones, followed by the lung, brain, liver and adrenal glands (45-48). As far as brain metastases are concerned adenocarcinoma is the commonest histological type which is connected with brain involvement (45). They can present as headache, vomiting, spasms, hemiparesis, dysfunction of cranial nerves or disorders of the visual field. These metastases can be, however, asymptomatic $(2,29)$. Metastatic spinal cord compression has also been observed (46). Bone metastases occur in up to $30-40 \%$ of patients with NSCLC. The most common metastatic sites are the bodies of the vertebrae, the pelvis and the femur. However, all bones are potential metastatic positions. These lesions appear radiographically as osteolytic lesions and very rarely as osteoblastic. Bone metastastic lesions cause skeletal pain, localized tenderness, elevated levels of calcium and alkaline phosphatase in serum $(2,29,33,47,48)$. Both brain and bone metastases are connected with poor prognosis. However, the use of brain MRI, the early detection of brain metastases and the use of new medicaments in bone metastases (ex. Zoledronic) have improved the survival of these patients. Liver metastases are also connected with poor survival rates. They are rarely associated with typical severe symptomatology (48). They can however cause symptoms such as weakness, anorexia, weight loss and epigastric pain. Liver enzymes, alkaline phosphatase and lactate dehydrogenase are elevated in those cases. Multiple nodules of the liver can be morphologically palpated during the clinical examination (33). The biliary tract obstruction by lymphnode metastases is a rare condition (48). Adrenal gland metastases are also possible to occur in patients with NSCLSC. They are usually discovered during staging procedures and they can rarely lead to renal insufficiency $(33,48)$.

Paraneoplastic Syndromes are clinical manifestations that are caused by the tumor but not due to local tumor expansion itself or the tumor metastases $(29,49)$. There are several paraneoplastic syndroms associated with lung cancer. The manifestations may be endocrine, neuromuscular or musculoskeletal, cardiovascular, cutaneous, hematologic, gastrointestinal, renal, or miscellaneous. They may precede other clinical manifestations, appear in advanced disease, be the first sign of the cancer disease or be a sign of recurrence of the disease after treatment. They are observed approximately in $10-20 \%$ of patients (50, 51). Motor-sensory neuropathy, arthritis, arthralgia, periarthritis, hypertrophic osteopathy, clubbing und pruritus can be observed (50). Hypertrophic osteopathy is characterized by painful swelling of the joints, which usually involves the ankles, knees, wrists and elbows. It is usually symmetrical. The clubbing is characterized by selective increase of connective tissue in the final phalanges of the fingers of upper and lower limbs. The frequency of clubbing is similar in both NSCLC and SCLC $(17 \%)(52,53)$. Patients can also develop hypercalcemia, because the tumor can secret a protein similar to Parathormone (PtHrP). Hypercalcemia is often found in squamous carcinomas and is an unfavorable prognostic sign. Clinically it can appear with anorexia, nausea, vomiting, constipation, palpitations, polyuria, polydipsia, adipsia, dehydration, fatigue and consciousness disorders $(29,54-56)$.

\section{TNM staging and Stadium of NSCLC}

The TNM (Tumor-Node-Metastasis) classification system of NSCLC is a very important tool for all physicians involved in oncological diseases for the evaluation of the prognosis and the planning of the suitable therapeutic procedures (57). The anatomical extent of the disease, the infiltration of lymph nodes and the presence of distant metastases should be identified during staging. The TNM classification and staging is performed through the diagnostic procedures and plays a significant role in the final treatment of the patient. It also enables the proper and effective communication between physicians of different specialties who are involved in the diagnosis and treatment of lung cancer $(57,58)$. In tables 2 and 3 the TNM classification and the Stadiums of the NSCLC by the $7^{\text {th }}$ revision are demonstrated.

Table 2. Differences between $6^{\text {th }}$ and $7^{\text {th }}$ TNM classification.

\begin{tabular}{|c|c|c|}
\hline \multicolumn{2}{|c|}{$7^{\text {th }}$ classification } & $\mathbf{6}^{\text {th }}$ classification \\
\hline \multicolumn{2}{|c|}{ Tumor (T) } \\
\hline $\begin{array}{c}\text { Tumor in diameter } \\
<2 \mathrm{~cm}\end{array}$ & $\mathrm{~T} 1$ & $\mathrm{~T} 1$ \\
\hline $2 \mathrm{~cm}<\mathrm{T}<3 \mathrm{~cm}$ & $\mathrm{~T} 1 \mathrm{~b}$ & $\mathrm{~T} 1$ \\
\hline $3 \mathrm{~cm}<\mathrm{T}<5 \mathrm{~cm}$ & $\mathrm{~T} 2 \mathrm{a}$ & $\mathrm{T} 2$ \\
\hline $5 \mathrm{~cm}<\mathrm{T}<7 \mathrm{~cm}$ & $\mathrm{~T} 2 \mathrm{~b}$ & $\mathrm{~T} 2$ \\
\hline $\mathrm{T}>7 \mathrm{~cm}$ & $\mathrm{~T} 3$ & $\mathrm{~T} 2$ \\
\hline $\begin{array}{c}\text { Nodules in the } \\
\text { same lobe }\end{array}$ & $\mathrm{T} 3$ & $\mathrm{~T} 1$ \\
\hline $\begin{array}{c}\text { Metastase in } \\
\text { ipsilateral lung } \\
\text { nodule }\end{array}$ & $\mathrm{T} 4$ & $\mathrm{~T}$ \\
\hline \multicolumn{2}{|c|}{} & $\mathrm{T}$ \\
\hline $\begin{array}{c}\text { Malignant pleural } \\
\text { effusion }\end{array}$ & Metastase (M) \\
\hline $\begin{array}{c}\text { Nodule in } \\
\text { contralateral lung }\end{array}$ & M1a & $\mathrm{M} 1$ \\
\hline Distant metastses & M1a & \\
\hline
\end{tabular}


Table 2a. $7^{\text {th }}$ TNM classification.

\begin{tabular}{|c|c|}
\hline \multicolumn{2}{|r|}{ Tumor $(\mathrm{T})$} \\
\hline Tx & $\begin{array}{l}\text { Primary tumor cannot be proven by imaging or } \\
\text { bronchoscopy despite the presence of malignant cells in } \\
\text { sputum or bronchial washings }\end{array}$ \\
\hline T0 & No evidence of primary tumor \\
\hline Tis & Carcinoma in situ \\
\hline $\mathrm{T} 1$ & $\begin{array}{l}\text { Tumor less than or equal to } 3 \mathrm{~cm} \text { in diameter surrounded by } \\
\text { lung or visceral pleura without an evidence of invasion of } \\
\text { the main bronchus }\end{array}$ \\
\hline T1a & Tumor less than or equal to $2 \mathrm{~cm}$ in dimension \\
\hline T1b & $\begin{array}{l}\text { Tumor greater than } 2 \mathrm{~cm} \text {, but less than } 3 \mathrm{~cm} \text { in greatest } \\
\text { dimension }\end{array}$ \\
\hline $\mathrm{T} 2$ & $\begin{array}{l}\text { Tumor in dimension greater than } 3 \mathrm{~cm} \text {, but less than } 7 \mathrm{~cm} \text { or } \\
\text { tumor involving any of the following features: } \\
\text { - Invasion of visceral pleura } \\
\text { - Atelectasis or obstructive pneumonitis that extends to the } \\
\text { hilar region, but does not involve the entire lung } \\
\text {-Invasion of main bronchus or } 2 \mathrm{~cm} \text { distal to the carina }\end{array}$ \\
\hline T2a & $\begin{array}{l}\text { Tumor greater than } 3 \mathrm{~cm} \text {, but less than or equal to } 5 \mathrm{~cm} \text { in } \\
\text { dimension }\end{array}$ \\
\hline $\mathrm{T} 2 \mathrm{~b}$ & Tumor greater than $5 \mathrm{~cm}$, but less than $7 \mathrm{~cm}$ in dimension \\
\hline T3 & $\begin{array}{l}\text { Tumor greater than } 7 \mathrm{~cm} \text { (in greater dimension) or tumor } \\
\text { invading: } \\
\text { - Chest wall, diaphragm, phrenic nerve, mediastinal pleura, } \\
\text { parietal pericardium } \\
\text { - Tumour in the main bronchus }<2 \mathrm{~cm} \text { distal to the carina } \\
\text { but without involvement of the carina } \\
\text {-Separate tumor nodule or nodules in the same lobe } \\
\text { - Associated atelectasis or obstructive pneumonitis of the } \\
\text { entire lung }\end{array}$ \\
\hline $\mathrm{T} 4$ & $\begin{array}{l}\text { Tumor of any size that invades one of the following: } \\
\text {-Mediastinum } \\
\text {-Heart } \\
\text {-Great vessels } \\
\text {-Trachea } \\
\text {-Recurrent laryngeal nerve } \\
\text {-Esophagus } \\
\text {-Vertebral body } \\
\text {-Carina or } \\
\text { - Separate tumor nodules in a different ipsilateral lobe }\end{array}$ \\
\hline \multicolumn{2}{|r|}{ Nodes $(\mathrm{N})$} \\
\hline $\mathrm{Nx}$ & Regional lymph nodes cannot be assessed \\
\hline N0 & No metastasis to regional lymph nodes \\
\hline N1 & $\begin{array}{l}\text { Metastasis in ipsilateral peribronchial and/or ipsilateral } \\
\text { hilar lymph nodes and intrapulmonary nodes, including } \\
\text { involvement by direct extension }\end{array}$ \\
\hline N2 & $\begin{array}{l}\text { Metastasis in ipsilateral mediastinal and/or subcarinal } \\
\text { lymph node(s) }\end{array}$ \\
\hline N3 & $\begin{array}{l}\text { Metastasis in contralateral mediastinal, contralateral hilar, } \\
\text { ipsilateral or contralateral scalene, or supraclavicular lymph } \\
\text { node(s) }\end{array}$ \\
\hline \multicolumn{2}{|r|}{ Metastases (M) } \\
\hline $\mathrm{Mx}$ & Distant metastases cannot be assessed \\
\hline M0 & No evidence of distant metastases \\
\hline M1a & $\begin{array}{l}\text {-Separate tumour nodule(s) in a contralateral lobe } \\
\text {-Tumour with pleural nodules } \\
\text {-Malignant pleural/ pericardial effusion }\end{array}$ \\
\hline M1b & Distant metastases \\
\hline
\end{tabular}

By the $7^{\text {th }}$ revision of the TNM classification several changes have been made concerning the $\mathrm{T}$ (Tumor) and M (Metastases) parameters. No changes on factor $\mathrm{N}$ (Nodules) were made. The $7^{\text {th }}$ edition attempts to correlate in a better and more effective way the disease with prognostic value and treatment strategy $(57,60)$. One of the main modifications of $\mathrm{T}$ factor concerns the $\mathrm{T} 1$ stage. The limit of $3 \mathrm{~cm}$ diameter of the primary tumor for $\mathrm{T} 1$ still exists. However, $\mathrm{T} 1$ is distinguished in $\mathrm{T} 1 \mathrm{a}$ and $\mathrm{T} 1 \mathrm{~b}$. This discrimination is based on the diameter of the tumor. If the primary tumor is smaller than or equal to $2 \mathrm{~cm}$ it is characterized according to the seventh staging as $\mathrm{T} 1 \mathrm{a}$. If the tumor is greater than $2 \mathrm{~cm}$ and less than or equal to $3 \mathrm{~cm}$ the $\mathrm{T}$ stage is characterized as $\mathrm{T} 1 \mathrm{~b}$. Tumors greater than $3 \mathrm{~cm}$ in diameter is characterized as T2. If the primary tumor is less or equal than $5 \mathrm{~cm}$, it is characterized as T2a. Bigger than $5 \mathrm{~cm}$ but less than $7 \mathrm{~cm}$ is characterized $\mathrm{T} 2 \mathrm{~b}$. If the tumor is greater in diameter than $7 \mathrm{~cm}$, then it is classified as T3. A primary tumor can also be classified as T3 by the presence of a malignant or malignant nodules in the same lobe. Radiologically is the display of these findings not frequent. However, by pathological staging these findings are frequent after surgical resection. By the previous TNM staging this stage of the disease was characterized as $\mathrm{T} 4$. The presence of the nodule or nodules in a different ipsilateral lobe of the lung is now considered by the $7^{\text {th }}$ revision as $\mathrm{T} 4$. Before it was considered as M1.

Table 3. Stadium of TNM according to the $7^{\text {th }}$ classification

\begin{tabular}{|l|l|l|l|l|l|}
\hline & N0 & N1 & N2 & N3 & M1-M1b \\
\hline T1a-T1b & IA & IIA & IIIA & IIIB & IV \\
\hline T2a & IB & IIA & IIIA & IIIB & IV \\
\hline T2b & IIA & IIB & IIIA & IIIB & IV \\
\hline T3 & IIB & IIIA & IIIA & IIIB & IV \\
\hline T4 & IIIA & IIIA & IIIB & IIIB & IV \\
\hline M1a-M1b & IV & IV & IV & IV & \\
\hline
\end{tabular}

With the $7^{\text {th }}$ TNM classification changes have occurred in the part of the metastases of the disease. Malignant metastases in the contralateral lung are considered as M1a. Also as M1a in the present TNM staging is regarded the malignant pleural effusion. In the previous staging the malignant pleural effusion was considered as T4. However, with this staging it showed poor prognosis, because of the pleural spread of disease regardless of regional lymph node. The presence of malignant pericardial effusion, the presence of pleural implants and metastase in the contralateral lung are also considered as M1a according to the $7^{\text {th }}$ TNM revision. Any other distal metastasis is mentioned as M1b (57-60).

A new revision of the TNM staging of the NSCLC is expected in late 2016. $(57,58)$. The lymph node involvement $(\mathrm{N})$ was not revised in the last $7^{\text {th }}$ 
classification. The collection of oncological data from cancer centers of Asia and Africa was incomplete for the last $7^{\text {th }}$ staging revision. For example not all countries, have the same possible means of therapeutical treatment of the patients due to financial issues or problems of any other nature. It should be also mentioned that for the $7^{\text {th }}$ revision the computer tomography was mainly used. By the following revision the PET/CT could also be used (58).

While waiting for the new $8^{\text {th }}$ TNM classification several ideas for changes have been proposed. More specifically Rami-Porta $\mathrm{R}$ et al. proposed a further subclassification of T1 tumors. T1 could be further classified in $\mathrm{T} 1 \mathrm{a}, \mathrm{T} 1 \mathrm{~b}$ and $\mathrm{T} 1 \mathrm{c}$ with $\mathrm{T} 1 \mathrm{a}$ having a diameter of less or equal to $1 \mathrm{~cm}, \mathrm{~T} 1 \mathrm{~b}$ greater than $1 \mathrm{~cm}$ and less or equal to $2 \mathrm{~cm}$ and T1c less or equal to $3 \mathrm{~cm}$. In addition, a new classification is proposed for $\mathrm{T} 2$ tumors. According to this proposal as T2 would be classified tumors which are greater than $3 \mathrm{~cm}$ and less or equal to $5 \mathrm{~cm}$. As a result, a new subdivision of $\mathrm{T} 2$ having as basis of $4 \mathrm{~cm}$ diameter has also been proposed. This could be $3 \mathrm{~cm}<\mathrm{T} 2 \mathrm{a} \leq 4 \mathrm{~cm}$ and $4 \mathrm{~cm}<\mathrm{T} 2 \mathrm{~b} \leq 5 \mathrm{~cm}$. As far as T3 tumors are concerned the upper diameter limit is proposed at $7 \mathrm{~cm}$, while $\mathrm{T} 4$ at greater than $7 \mathrm{~cm}$. On the other hand, the invasion of the main bronchus regardless of the distance from the carina is proposed to be classified as T2. T2 is also proposed to include the atelectasis or pneumonitis of the lung regardless of its extent. The diaphragm invasion is proposed to be considered as T4 in the $8^{\text {th }}$ classification and not T3 as in it was classified in the $7^{\text {th }}$ revision. Moreover, Rami-Porta $\mathrm{R}$ et al. proposed that the mediastinal pleura invasion should not play any role in assessing the $\mathrm{T}$ stadium of the disease (61). As far as the $\mathrm{M}$ factor is concerned Eberhardt WE et al. have proposed a new classification. Only single metastases in single organs should entitled as M1b. An other M1c category is also proposed to be made. This new category would include multiple metastases in one or multiple organs. Cases with pleural/pericardial effusions, contralateral/bilateral lung nodules, contralateral/bilateral pleural nodules or a combination of multiple of these parameters should be further classified as M1a (62). What is more, for the forthcoming $8^{\text {th }}$ classification Asamura et al. proposed the preservation of the $\mathrm{N}$ classification, claiming that it can adequately predict the prognosis of the cancer disease. However, in this area a further classification has also been proposed (N1a, N1b, N2a, N2b, and N3) (63). In addition, Detterbeck FC et al. proposed an inclusion of LC types that are presented as multiple pulmonary sites or multiple nodules with ground glass or lepidic features or LC with a pneumonic type of involvement in the $8^{\text {th }} \mathrm{TNM}$ classification $(64,65)$. The health professionals who are engaged with the therapy and diagnosis of NSCLC and generally LC anticipate the upcoming TNM classification as it is expected to change the therapeutic approach of one to six patients $(57,58)$. Regarding the methods of staging, there are still issues with the usage of PET-CT for the evaluation of lesions (primary mass or lymph nodes $<1 \mathrm{~cm}$ ) where the "negative" results could be false negative or there are cases where we have false positive. There are cases where for peripheral lesions $<3 \mathrm{~cm}$ with negative mediastinum lymph nodes $<1 \mathrm{~cm}$ PET-CT has a high rate of false negative results.[66-69] Therefore, endobronchial ultrasound (EBUS) or mediastinoscopy should be considered again in such cases. Another issue regarding the EBUS method is the lack of appropriate expertise and application by many canters. For example, it has been stated that at least three passes are necessary in order to have optimal material for evaluation, 70-72 however; some centers publish series of patients undergoing EBUS under mild anesthesia or even local anesthesia. Caution should be taken when publishing studies from centers performing two-three EBUS procedures when compared to centers performing 20-40 per week. Figures 3 . Therefore, probably there are several false negative results, in some centers since the method under which biopsies are performed are not safe for the patient and certainly the sample is not sufficient. [73-74] When EBUS is used just for diagnosis, general anesthesia is not always necessary, however; staging with small lymph nodes $<1.2 \mathrm{~cm}$ is another issue and the method of sedation is very important both for the safety of the patient and for the efficiency of the EBUS user. Moreover; how often can somebody use an EUS system next to an EBUS procedure.

\section{Conclusion}

The NSCLC is a multifactorial disease. Therefore, the approach of the disease should be multidisciplinary. The symptomatology is almost always not specific for the disease. For this reason, a careful approach should be always carried out and the tumor disease should be always in mind of the clinician. By the first and diagnostic approach of the disease the patient should be thoroughly asked, investigated, asked for the suspected causes and all possible risk factors should be taken into consideration. Last but not least, it is highly important that all medical professionals that deal with the diagnosis and the treatment of the NSCLC are familiar with the actual staging classification system. 


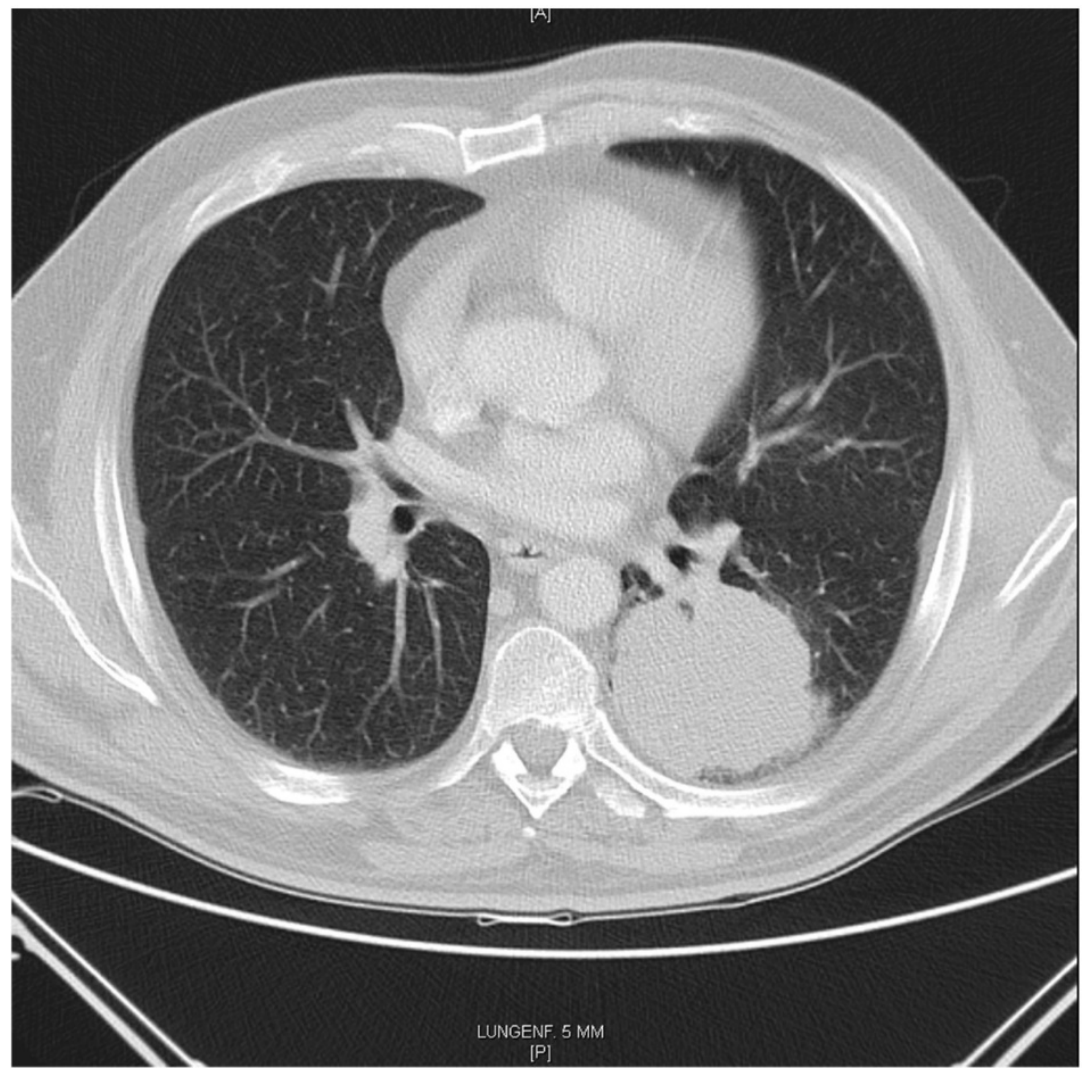

Figure 1. Squamous cell carcinoma left. Surgically treated with VATS Lobectomy. PT3N1. Tumor: $8 \times 7,5 \times 8 \mathrm{~cm}$, infiltration of Visceral pleura and infiltration of intrapulmonary nodes.

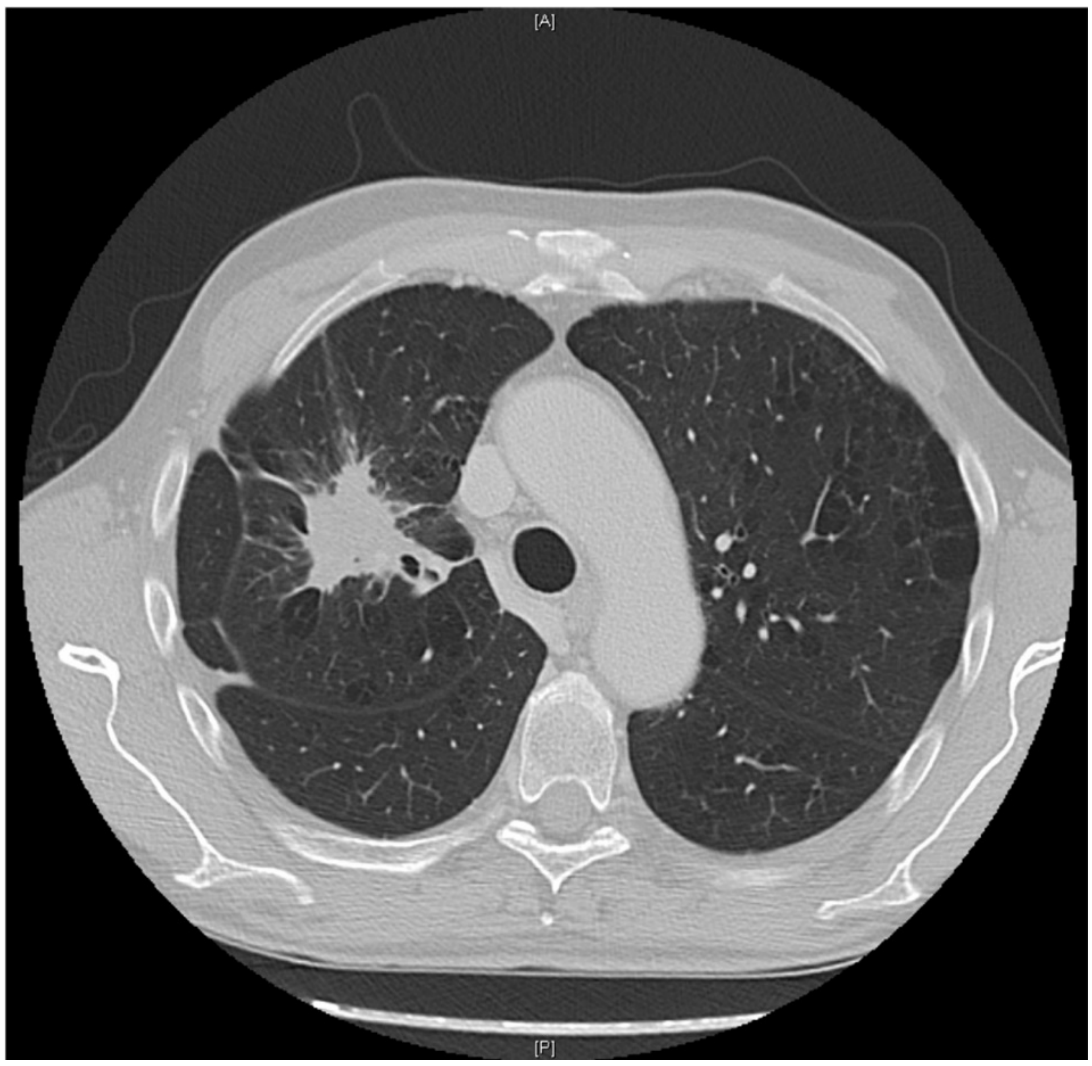

Figure 2. Adenocarcinoma.surgically treated with lobectomy with posterolateral thoracotomy. PT1aN2 


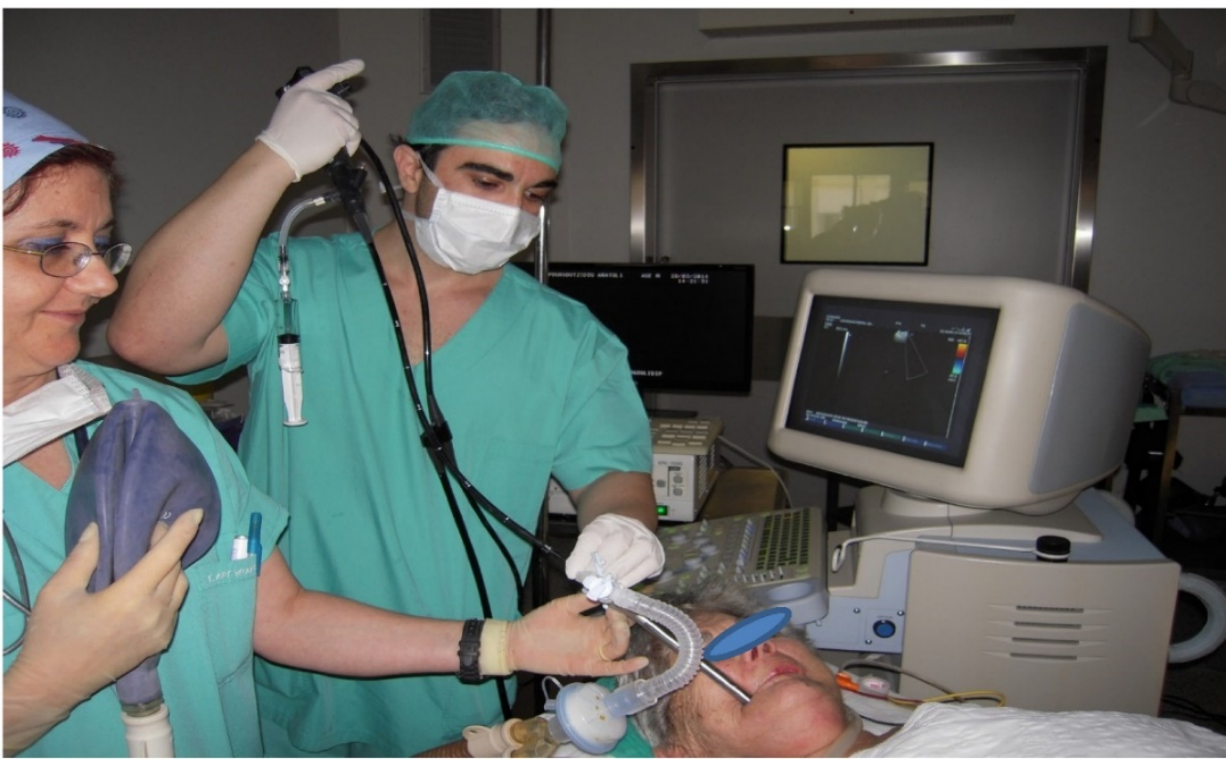

Figure 3. EBUS procedure with rigid bronchoscope PENTAX EBUS SYSTEM, general under Jet-Ventilation. Saint Luke Private Hospital (Figure by Paul Zarogoulidis performing EBUS).

\section{Conflict of Interest}

None to declare.

\section{References}

1. Molina RJ, Yang P, Cassivi DS, et al. Non-Small Cell Lung Cancer: Epidemiology, Risk Factors, Treatment, and Survivorship. Mayo Clin Proc. 2008 May ; 83(5): 584-594

2. [Internet] Winston W. Non-Small Cell Lung Cancer. http://emedicine.medscape.com/article/279960-overview\#showall

3. Eriksen M, Mackay J, Ross H. The tobacco atlas; 4th ed. Atlanta, GA: American Cancer Society. 2012. Available at http://www.tobaccoatlas.org

4. Ridge C, McErlean A, Ginsberg M. Epidemiology of Lung Cancer. Semin Intervent Radiol 2013;30:93-98

5. Ferlay J, Shin HR, Bray F, et al. GLOBOCAN 2008, Cancer Incidence and Mortality Worldwide: IARC CancerBase No 10. Lyon, France: International Agency for Research on Cancer. 2010. Available at: http://globocan.iarc.fr

6. [Internet] American Cancer Society. Cancer Facts \& Figures 2016. http://www.cancer.org/acs/groups/content/@research/documents/d ocument/acspc-047079.pdf

7. Proctor RN. The history of the discovery of the cigarette-lung cancer link: evidentiary traditions, corporate denial, global toll. Tob Control. 2012 Mar;21(2):87-91.

8. Proctor RN. The global smoking epidemic: a history and status report. Clin Lung Cancer. 2004 May;5(6):371-6.

9. Lubin JH, Caporaso NE. Cigarette smoking and lung cancer: modeling total exposure and intensity. Cancer Epidemiol Biomarkers Prev. 2006 Mar;15(3):517-23.

10. Hecht SS. Cigarette smoking and lung cancer: chemical mechanisms and approaches to prevention. Lancet Oncol. 2002 Aug;3(8):461-9.

11. Loeb LA, Ernster VL, Warner KE, et al. Smoking and lung cancer: an overview. Cancer Res. 1984 Dec;44(12 Pt 1):5940-58.

12. Kontakiotis T, Manolakoglou N, Zoglopitis F et al. Epidemiologic trends in lung cancer over two decades in Northern Greece: an analysis of bronchoscopic data. Monaldi Arch Chest Dis. 2009 Dec;71(4):147-52.

13. Besaratinia A, Pfeifer GP. Second-hand smoke and human lung cancer. Lancet Oncol. 2008; 9(7): 657-666

14. Claire H Kim CH, Yuan-Chin Amy Lee, Rayjean J Hung et al. Exposure to secondhand tobacco smoke and lung cancer by histological type: a pooled analysis of the International Lung Cancer Consortium (ILCCO). Int J Cancer. 2014; 135(8): 1918-1930.
15. Brennan P, Buffler P, Reynolds P, et al. Second hand smoke exposure in adulthood and risk of lung cancer among never smokers: a pooled analysis of two large studies. Int J Cancer 2004; 109: 125-131

16. Sethi TK, El-Ghamry MN, Kloecker GH. Radon and lung cancer. Clin Adv Hematol Oncol. 2012 Mar;10(3):157-64

17. Lubin JH. Studies of radon and lung cancer in North America and China. Radiat Prot Dosimetry. 2003;104(4):315-9.

18. Turner MC, Krewski D, Chen Y, et al. Radon and lung cancer in the American Cancer Society cohort. Cancer Epidemiol Biomarkers Prev. 2011 Mar;20(3):438-48. doi: 10.1158/1055-9965.EPI-10-1153. Epub 2011 Jan 6.

19. Samet JM, Hornung RW. Review of radon and lung cancer risk. Risk Anal. 1990 Mar;10(1):65-75.

20. Heintz NH, Yvonne $\mathrm{M}$. et al. Asbestos, Lung Cancers, and Mesotheliomas. From Molecular Approaches to Targeting Tumor Survival Pathways. Am J Respir Cell Mol Biol. 2010 Feb; 42(2): 133-139.

21. Nielsen LS, Bælum J, Rasmussen J, et al. Occupational asbestos exposure and lung cancer--a systematic review of the literature. Arch Environ Occup Health. 2014;69(4):191-206.

22. Kirk G, Merlo C. HIV Infection in the Etiology of Lung Cancer. Confounding, Causality, and Consequences. Proc Am Thorac Soc. 2011 Jun $1 ; 8(3)$ : 326-332

23. Mani D, Haigentz M Jr, Aboulafia DM. Lung cancer in HIV Infection. Clin Lung Cancer. 2012 Jan;13(1):6-13.

24. Denholm R, Schüz J, Straif Ket al. Is previous respiratory disease a risk factor for lung cancer? Am J Respir Crit Care Med. 2014 Sep 1;190(5):549-59.

25. Powell HA1, Iyen-Omofoman B, Baldwin DR, et al. Chronic obstructive pulmonary disease and risk of lung cancer: the importance of smoking and timing of diagnosis. J Thorac Oncol. 2013 Jan;8(1):6-11.

26. $\mathrm{Yu} \mathrm{YH}$, Liao $\mathrm{CC}, \mathrm{Hsu} \mathrm{WH}$,et al. Increased lung cancer risk among patients with pulmonary tuberculosis: a population cohort study. J Thorac Oncol. 2011 Jan;6(1):32-7

27. Li N, Shao K, Chen Z, et al. The impact of positive cancer family history on the clinical features and outcome of patients with non-small cell lung cancer. Fam Cancer. 2011 Jun;10(2):331-6.

28. Uramoto $H$, Sugio $K$, Oyama $T$, et al. Expression of the p53 family in lung cancer. Anticancer Res. 2006;26(3A):1785-90.

29. [Internet] American cancer society. Non small cell lung cancer. http://www.cancer.org/acs/groups/cid/documents/webcontent/003 115-pdf.pdf

30. [Internet] US National Library of Medicin. http://www.ncbi.nlm.nih.gov/pubmedhealth/PMH0032567/\#CDR000 $0062956 \_266$

31. Iyer S, Roughley A, Rider A, et al. The symptom burden of non-small cell lung cancer in the USA: a real-world cross-sectional study. Support Care Cancer. 2014 Jan;22(1):181-7. 
32. Kvale PA. Chronic cough due to lung tumors: ACCP evidence-based clinical practice guidelines. Chest. 2006 Jan;129(1 Suppl):147S-153S.

33. Sugarbaker D, Raphael Bueno R, Colson Y, et al. Adult Chest Surgery. ISBN 978-0-07-145912-9

34. Morgensztern D, Waqar S, Subramanian J, et al. Prognostic impact of malignant pleural effusion at presentation in patients with metastatic non-small-cell lung cancer. J Thorac Oncol. 2012 Oct;7(10):1485-9.

35. Vencevičius V, Cicènas S. Spontaneous pneumothorax as a first sign of pulmonary carcinoma. World J Surg Oncol. 2009; 7: 57.

36. Simmons C, MacLeod N, Laird B. Clinical Management of Pain in Advanced Lung Cancer. Clin Med Insights Oncol. 2012; 6: 331-346.

37. Gale ME, Birnbaum SB, Gale DR, et al. Esophageal invasion by lung cancer: CT diagnosis. J Comput Assist Tomogr. 1984 Aug;8(4):694-8.

38. Camidge DR. The causes of dysphagia in carcinoma of the lung. J R Soc Med. 2001 Nov; 94(11): 567-572.

39. Vara-Castrodeza A, Torrego-García JC, Puertas-Álvarez JL, et al. Pontine metastases as a cause of dysphagia in lung carcinoma. Clin Transl Oncol. 2005;7(11):512-4

40. Tamura A, Matsubara O, Yoshimura N, et al. Cardiac metastasis of lung cancer. A study of metastatic pathways and clinical manifestations. Cancer. 1992 Jul 15;70(2):437-42.

41. Stroppa EM, Malagoli A, Cavanna L. Tachyarrhythmia secondary to cardiac metastasis as first presentation of non-small-cell lung cancer. Thoracic Cancer 2012;3: 197-19

42. Panagopoulos N, Leivaditis V, Koletsis E, et al. Pancoast tumors: characteristics and preoperative assessment. J Thorac Dis. 2014 Mar; 6(Suppl 1): S108-S115.

43. Kovach SG, Huslig EL. Shoulder pain and Pancoast tumor: a diagnostic dilemma. J Manipulative Physiol Ther. 1984 Mar;7(1):25-31.

44. Hsu JW, Chiang CD, Hsu WH, et al. Superior vena cava syndrome in lung cancer: an analysis of 54 cases. Gaoxiong Yi Xue Ke Xue Za Zhi. 1995 Oct;11(10):568-73.

45. Ali a, Goffin JR, Arnold A. Survival of patients with non-small-cell lung cancer after a diagnosis of brain metastases. Curr Oncol. 2013 Aug; 20(4): e300-e306.

46. Rades D, Douglas S, Veninga $\mathrm{T}$ et al. Metastatic spinal cord compression in non-small cell lung cancer patients. Prognostic factors in a series of 356 patients. Strahlenther Onkol. 2012 Jun;188(6):472-6.

47. Rossi A, Gridelli C, Ricciardi S, et al. Bone metastases and non-small cell lung cancer: from bisphosphonates to targeted therapy. Curr Med Chem. 2012;19(32):5524-35.

48. TOMOHIRO TAMURA, KOICHI KURISHIMA, KENSUKE NAKAZAWA, et al. Specific organ metastases and survival in metastatic non-small-cell lung cancer. Mol Clin Oncol. 2015 Jan; 3(1): 217-221.

49. Pelosof LC, Gerber DE. Paraneoplastic Syndromes: An Approach to Diagnosis and Treatment. Mayo Clin Proc. 2010 Sep; 85(9): 838-854.

50. Campanella N, Moraca A, Pergolini M, et al. Paraneoplastic syndromes in 68 cases of resectable non-small cell lung carcinoma: can they help in early detection? Med Oncol. 1999 Jul;16(2):129-33.

51. Cosar-Alas R, Yurut-Caloglu V, Karagol H, et al. Paraneoplastic syndrome of non-small cell lung carcinoma: a case with pancytopenia, leukocytoclastic vasculitis, and hypertrophic osteoarthropathy. Lung Cancer. 2007 Jun;56(3):455-8. Epub 2007 Feb 12.

52. XINYU QIAN, JING QIN. Hypertrophic pulmonary osteoarthropathy with primary lung cancer. Oncol Lett. 2014 Jun; 7(6): 2079-2082.

53. Erkan ML, Findik S, Kandemir B, et al. The prevalence of clubbing in different types of lung cancer. Ann Saudi Med. 2002;22(5-6):295-6.

54. Hassan BA, Yusoff ZB, Hassali MA, et al. Impact of chemotherapy on hypercalcemia in breast and lung cancer patients. Asian Pac J Cancer Prev. 2012;13(9):4373-8.

55. Lazaretti-Castro $\mathrm{M}$, Kayath $\mathrm{M}$, Jamnik $\mathrm{S}$, et al. [Prevalence of hypercalcemia in patients with lung cancer]. Rev Assoc Med Bras. 1993;39(2):83-7.

56. Matsumoto J, Kojima T, Shimizu Tet al. A case of lung cancer with hypercalcemia which was incidentally complicated with primary hyperparathyroidism due to parathyroid adenoma. Ann Thorac Cardiovasc Surg. 2002 Jun;8(3):151-3.

57. UyBico SJ, Wu CC, Suh RD, et al. Lung cancer staging essentials: the new TNM staging system and potential imaging pitfalls. Radiographics. 2010 Sep;30(5):1163-81.
58. Saeed Mirsadraee, Dilip Oswal, Yalda Alizadeh, et al. The 7th lung cancer TNM classification and staging system: Review of the changes and implications. World J Radiol. 2012 Apr 28; 4(4): 128-134.

59. Nair A, Klusmann MJ, Jogeesvaran KH, et al. Revisions to the TNM staging of non-small cell lung cancer: rationale, clinicoradiologic implications, and persistent limitations. Radiographics. 2011;31(1):215-38.

60. Rami-Porta R, Bolejack V, Goldstraw P. The new tumor, node, and metastasis staging system. Semin Respir Crit Care Med. 2011 Feb;32(1):44-51

61. Rami-Porta R, Bolejack V, Crowley J, et al. The IASLC Lung Cancer Staging Project: Proposals for the Revisions of the T Descriptors in the Forthcoming Eighth Edition of the TNM Classification for Lung Cancer. J Thorac Oncol. 2015 Jul;10(7):990-1003.

62. Eberhardt WE, Mitchell A, Crowley J, et al. The IASLC Lung Cancer Staging Project: Proposals for the Revision of the M Descriptors in the Forthcoming Eighth Edition of the TNM Classification of Lung Cancer. J Thorac Oncol. 2015 Nov;10(11):1515-22.

63. Asamura H, Chansky K, Crowley J, et al. The International Association for the Study of Lung Cancer Lung Cancer Staging Project: Proposals for the Revision of the N Descriptors in the Forthcoming 8th Edition of the TNM Classification for Lung Cancer. J Thorac Oncol. 2015 Dec;10(12):1675-84.

64. Detterbeck FC, Marom EM, Arenberg DA, et al. The IASLC Lung Cancer Staging Project: Background Data and Proposals for the Application of TNM Staging Rules to Lung Cancer Presenting as Multiple Nodules with Ground Glass or Lepidic Features or a Pneumonic Type of Involvement in the Forthcoming Eighth Edition of the TNM Classification. J Thorac Oncol. 2016 May;11(5):666-80

65. Detterbeck FC, Nicholson AG, Franklin WA, et al. The IASLC Lung Cancer Staging Project: Summary of Proposals for Revisions of the Classification of Lung Cancers with Multiple Pulmonary Sites of Involvement in the Forthcoming Eighth Edition of the TNM Classification. J Thorac Oncol. 2016 May;11(5):639-50.

66. Jin X, Liang N, Wang M, Meng Y, Jia B, Shi X, et al. Integrin Imaging with 99mTc-3PRGD2 SPECT/CT Shows High Specificity in the Diagnosis of Lymph Node Metastasis from Non-Small Cell Lung Cancer. Radiology. 2016: 150813. doi:10.1148/radiol.2016150813.

67. Tachi R, Hattori A, Matsunaga T, Takamochi K, Oh S, Suzuki K. The impact on the prognosis of unsuspected N2 disease in non-small-cell lung cancer: indications for thorough mediastinal staging in the modern era. Surgery today. 2016. doi:10.1007/s00595-016-1372-y.

68. Carter BW, Benveniste MF, Betancourt SL, de Groot PM, Lichtenberger JP, 3rd, Amini B, et al. Imaging Evaluation of Malignant Chest Wall Neoplasms. Radiographics : a review publication of the Radiological Society of North America, Inc. 2016: 150208. doi:10.1148/rg.2016150208.

69. Lee JW, Na JO, Kang DY, Lee SY, Lee SM. Prognostic Significance of FDG Uptake of Bone Marrow on PET/CT in Patients With Non-Small-Cell Lung Cancer After Curative Surgical Resection. Clinical lung cancer. 2016. doi:10.1016/j.cllc.2016.07.001.

70. Wahidi MM, Herth F, Yasufuku K, Shepherd RW, Yarmus L, Chawla M, et al. Technical Aspects of Endobronchial Ultrasound-Guided Transbronchial Needle Aspiration: CHEST Guideline and Expert Panel Report. Chest. 2016; 149: 816-35. doi:10.1378/chest.15-1216.

71. Yarmus L, Akulian J, Gilbert C, Feller-Kopman D, Lee HJ, Zarogoulidis $\mathrm{P}$, et al. Optimizing endobronchial ultrasound for molecular analysis. How many passes are needed? Annals of the American Thoracic Society. 2013; 10: 636-43. doi:10.1513/AnnalsATS.201305-130OC.

72. Feller-Kopman D, Yarmus L. Training in interventional pulmonology. Seminars in respiratory and critical care medicine. 2014; 35: 631-5. doi:10.1055/s-0034-1395793.

73. Fielding D, Phillips M, Robinson P, Irving L, Garske L, Hopkins P, et al. Advanced interventional pulmonology procedures: training guidelines from the Thoracic Society of Australia and New Zealand. Respirology. 2012; 17: 1176-89. doi:10.1111/j.1440-1843.2012.02253.x.

74. Lee HJ, Sachdeva A. Training program of interventional pulmonology fellowships: USA. Journal of thoracic disease. 2015; 7: S415-7. doi:10.3978/j.issn.2072-1439.2015.11.55. 